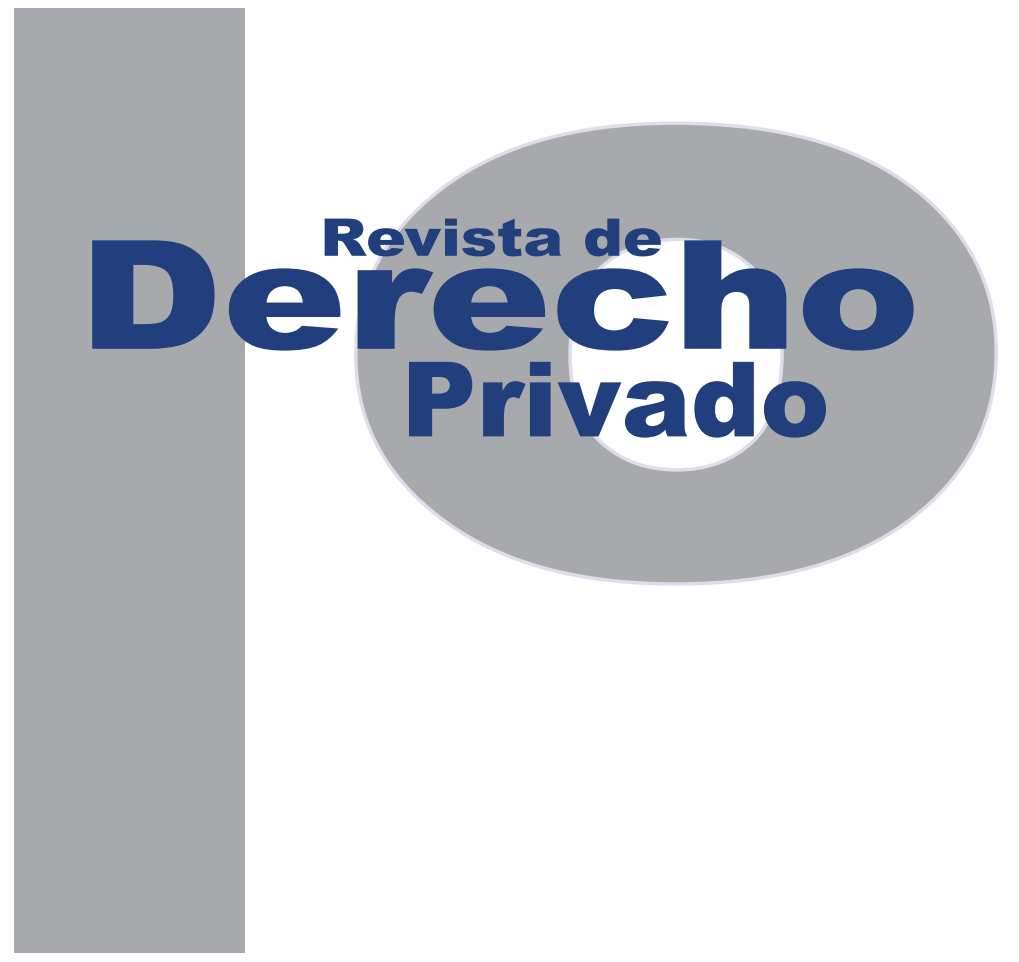

\title{
EL MÉTODO NEOCONSTITUCIONAL DE LA DIGNIDAD EN EL DERECHO PRIVADO: UNA APROXIMACIÓN A LA IGUALDAD DE GENÉRO EN EL ÁMBITO DE LAS RELACIONES FAMILIARES HOMOPARENTALES
}

\author{
LUIS Miguel Hoyos Rojas
}

Universidad de los Andes

Facultad de Derecho

Revista de Derecho Privado N. ${ }^{\circ} 47$

Enero - Junio de 2012. ISSN 1909-7794 


\title{
El método neoconstitucional de la dignidad en el derecho privado: una aproximación a la igualdad de genéro en el ámbito de las relaciones familiares homoparentales
}

\author{
Luis Miguel Hoyos Rojas ${ }^{1}$
}

\begin{abstract}
RESUMEN
Los avances significativos que han establecido el Derecho constitucional y el neoconstitucionalismo ideológico, para efectos de fijar una extensión de derechos aplicables a formas que tradicionalmente fueron entendidas como atípicas, de frente al ordenamiento común, son muestra fehaciente de una evolución del Derecho privado-familiar. Desde esta perspectiva, se presentará la estructura básica de las decisiones de la Corte Constitucional colombiana que reconocieron jurídicamente a las parejas del mismo sexo y que les confirieron un notable número de derechos, como antecedente de un modelo homologable a cualquier forma del pensamiento jurídico y social, que condescienda exterminar la problemática del reconocimiento jurídico de
\end{abstract}

\begin{abstract}
Significant progress has established the Constitutional Law and Ideological neoconstitutionalism, for purposes of determining an extension of duties on forms that were traditionally understood as "atypical" in front of the common order are irrefutable evidence of an evolution of Private Law-Family. From this perspective, we present the basic structure of the decisions of the Colombian Constitutional Court to legally recognize same-sex couples and that it conferred a significant number of rights, such as history of a conforming model in any form of legal thought and social, who condescend to exterminate the issue of legal recognition of same-sex couples, as seen from the field of gender equality, relationship. This will consider the arguments that
\end{abstract}

1 Licenciado en Ciencias Sociales y especialista en Género-Estudios Socioculturales, del Pontifical Bible College Internacional - Seminary Reina Valera Webster College of Humanities (Estados Unidos). (LL.S) Summa Cum Laude en Derecho Constitucional y Neoconstitucionalismo de la Escuela de Derecho de la Universidad de Chile. Egresado del Programa de Derecho de la Universidad del Norte (Barranquilla, Colombia). Profesor asociado en Dogmática Filosófica, Cultural y Teológica en Pontifical Bible College e International Bible Institute de Bogotá D.C. Investigador sociojurídico en el área de Género, Derecho Sustantivo y Contencioso Constitucional. Suscrito a la Revista de Estudios Latinoamericanos del David Rockefeller Center for Latin American Studies, Harvard University (Estados Unidos). Miembro del Institute for Cultural Studies para la Investigación en Género (Colombia). Fundador y miembro de la Asociación Colombiana de Derecho Constitucional y Antropología Social. hoyosIm@hotmail.com 
las parejas del mismo sexo, visto desde el ámbito de la igualdad de género-relación familiar. De esta manera, se considerarán los argumentos que permiten afirmar que este conjunto de sentencias componen un paso importante hacia la supresión de la discriminación que existió contra las parejas del mismo sexo, como presentación de los elementos constitutivos del modelo de la dignidad, novación jurídica que ofrece una clara y completa solución-explicación al problema del reconocimiento de nuevas formas jurídicas en materia familiar, concibiendo al principio de la dignidad, como método del nuevo Derecho privado constitucional.

Palabras clave: Derecho privado constitucional, Corte Constitucional, dignidad, neoconstitucionalismo, persona, familia, género e igualdad. say that this set of statements make up a significant step towards eliminating discrimination that existed against same-sex couples, as presenting the constituent elements of the model of dignity, legal innovation that provides a clear and complete explanation of the problem solution, the recognition of new forms of legislation in family matters. Conceiving the principles of dignity, as Method's new Constitutional Private Law.

Keywords: Private Law-Constitutional Law, Constitutional Court, Dignity, neoconstitutionalism, Person, Family, Gender and Equality. 
Sumario

Introducción - I. LA IGUALDAD DE GÉNERO EN EL NEOCONSTITUCIONALISMO - II. INICIO DEL ENFOQUE DE LA IGUALDAD DE GÉNERO: EL RECONOCIMIENTO JURÍDICO DE LOS DERECHOS DE LAS PAREJAS DEL MISMO SEXO EN COLOMBIA. RECORRIDO JURISPRUDENCIAL - III. EL MÉTODO NEOCONSTITUCIONAL DE LA DIGNIDAD EN EL ÁMBITO DE LAS RELACIONES FAMILIARES Y DE GÉNERO EN COLOMBIA - IV. EL MÉTODO NEOCONSTITUCIONAL DE LA DIGNIDAD Y LA SENTENCIA C-577 DE 2011 - V. CONCLUSIONES - Bibliografía. 
Introducción

Hablar de igualdad de sexos o, como es más frecuentemente aceptado, de igualdad de género, es referirse a un objetivo contra una realidad de discriminaciones y segregación social (Aznar y Cánovas, 2008). Una de las más abundantes y tácitas maneras de violación de los derechos humanos fundamentales, es el no reconocimiento jurídico de formas ajustables a lo que usualmente designamos "género". Éste es un problema universal, pero para vislumbrar mejor los patrones y sus causas, y por lo tanto excluirlos, se acuerda partir del conocimiento de las particularidades históricas y socioculturales de cada contexto delimitado.

Por consiguiente, es necesario reflexionar sobre qué responsabilidades y derechos ciudadanos se les reconocieron a las mujeres en cada sociedad, en comparación con los que se les reconocieron a los hombres, y las pautas de relación que entre ellos se establecieron. Pero, aunque la discriminación hacia la mujer o el hombre fueron el inicio de este tema coyuntural y de antemano las relaciones derivadas, hoy la discriminación tomó la contextura hacia las esferas del Derecho de familia, particularmente, "las relaciones derivadas del núcleo familiar y sus afectes establecidas". Por lo que, en efecto, el tema de la igualdad de género se analiza al presente desde el método de la ciencia del Derecho constitucional, sobre las nuevas relaciones de la familia: "sus nuevos intereses, nuevos sujetos y las nuevas formas jurídicas", que en nociones de la escolástica civilista arraigada, estrictamente eran inconcebibles.
Se trata de una nueva forma del discurso y el análisis jurídico, de una representación no creída por el tradicional Derecho de familia, donde se acomete una lucha por el reconocimiento jurídico y social que externaliza, todavía, aquellas diferencias y privilegios que a lo largo de la historia se han pretendido para justificar un solo modelo familiar, por razones étnicas, morales, religiosas y de sexo o de mérito dignificante; pero hoy sabemos que éstas no tienen fundamento alguno y que generan desequilibrios perjudiciales para todos, aunque algunos sigan pensando que esos desequilibrios instituyen algo natural. "Es hombre y mujer y ese es el modelo superior original" (Santo Tomás, 1968), etc.

La igualdad de sexos o igualdad de género, vista desde el reconocimiento de las nuevas formas familiares, entiende en Colombia una concepción que instala un enfoque ecuánime, que alentado por un modelo de Poder Judicial activista, permite tutelar los derechos humanos para lograr su plena vigencia práctica. En esta perspectiva, esta nueva visión del ordenamiento jurídico reclama una apariencia institucional de los jueces, en particular de los tribunales constitucionales, que podríamos definir como activismo judicial, y que tiene como soporte normativo los derechos humanos constitucionalizados y/o reconocidos en los documentos internacionales. Este punto de vista, aplicado a la igualdad de sexos o igualdad de género, es propio del neoconstitucionalismo liberal (Carbonell, 2003), que logra plantear el complejo y difícil tema de la misión de los jueces, especialmente de quienes tienen a su cargo el control de 
constitucionalidad, como citados a cumplir una democracia constitucional.

Así las cosas, el neoconstitucionalismo ideológico plantea y promueve una nueva relación del Poder Judicial con los demás órganos de gobierno y con la sociedad civil, para el logro de la vigencia efectiva de los derechos humanos. Los jueces deben controlar y aun suplir a los demás poderes para garantizar los derechos y hacer efectivas las promesas constitucionales. En el caso colombiano, la Corte Constitucional en uso del control de constitucionalidad sobre asuntos civiles, ha creado un estatus jurídico de constitucionalidad respecto a los derechos de las parejas del mismo sexo, punto de partida del discurso de la igualdad de género en materia familiar.

La anterior construcción jurisprudencial, unida al carácter fundamental que posee el Derecho constitucional (Sáchica, 2000) ha decretado intrínsecamente una regulación a través de principios y valores que osan ir más allá de la simple legalidad que inculcó en sus orígenes la interpretación y aplicación de la escolástica civilista (Estrada-Vélez, 2005).

Se trata, entonces, de un conjunto de sentencias, reglas y principios, donde el máximo tribunal de constitucionalidad afronta el tema de los derechos de las minorías sexuales como punto de la igualdad de género, para ofrecer un bloque de argumentos en la constitucionalización jurisprudencial del estatus político-jurídico que correspondería a las parejas del mismo sexo, de frente al Derecho civil aplicado en una democracia constitucional-liberal (Camargo, 1983).
En este aspecto, la Corte Constitucional ha dado pasos imprescindibles para eliminar la discriminación que existe en Colombia respecto al género y, de ello, las relaciones familiares derivadas, justificándose en la política del Estado apropiada bajo la Constitución de 1991 (Sentencia T-190: Corte Constitucional, 2010). Las sentencias C-075 de 2007, C-811 de 2007, T-856 de 2007, C-336 de 2008, C-798 de 2008, T-1241 de 2008, C-029 de 2009 y el reciente fallo C-577 de 2011, registraron de forma originaria en Colombia la existencia jurídica de las parejas del mismo sexo y la aplicación emblemática de un conjunto importante de derechos y obligaciones constitucionales y legales. Derechos que circunscriben tópicos como la dignidad humana, la igualdad, la salud, las pensiones y la nacionalidad de los miembros de las parejas del mismo sexo (Bonilla, 2008). Así la Corte funda en este ligado jurisprudencial, un giro cardinal a la jurisprudencia y la posición doctrinal en el ordenamiento jurídico civil colombiano sobre los derechos de las parejas del mismo sexo, instalando el enfoque propio del neoconstitucionalismo liberal en materia de género; como nueva forma de protección esencial a la luz de los derechos fundamentales de las recientes formas familiares.

El hecho, entonces, es admitir que estas sentencias aunque ratificadas por unanimidad 0 mayorías notables en una Corte Constitucional, compuesta por varios magistrados con difíciles perspectivas políticas, expresan importantes novaciones que se han traducido en cambios sociales y culturales dentro de la interpretación del ordenamiento privado-familiar en Colombia, 
proveyendo un comienzo garantista en nuestro país en torno a la valoración social de las minorías sexuales. Este giro jurídico a manera de cambio, se corrobora ipso facto en que las sentencias por lo menos no fueron objeto de cuestionamientos -morales o religiosos- por vastas secciones de la población.

De esta manera, las razones que justifican este contiguo de sentencias permitirán exteriorizar un método nacido del enfoque neoconstitucional liberal colocado por la Corte, para percibir, justipreciar y reconocer jurídicamente las parejas del mismo sexo en el plano de la igualdad de género. Fijando la línea jurisprudencial, la Corte Constitucional reconoció la existencia jurídica de las parejas del mismo sexo, después de una compleja lucha sobre modelos y paradigmas sociales en tensión, logrando una reivindicación del ordenamiento civil para efectos de no ofuscar los derechos de esta clase de minorías.

En conclusión, examinaré cómo la dignidad, producto del enfoque neoconstitucional liberal enclavado por la doctrina constitucional de la Corte, es presentada como el método del nuevo Derecho privado constitucional, el cual promete considerables preeminencias, pues identifica el problema que está en juego de la manera más clara, estrecha, llana y comprensiva posible, siendo por tanto una herramienta del Derecho civil-familiar contemporáneo que explicita las dificultades para erradicar el problema político y jurídico que envuelve el no reconocimiento jurídico de las parejas del mismo sexo y nuevas formas jurídicas alternas en materia de género. Instituyendo éste, un juicio sólido que busca contrarrestar cualquier forma de discriminación jurídica que determine la violación de los derechos humanos fundamentales. Método que logra la homologación de diferentes formas de pensar en la sociedad, dado el extenso contenido del principio de la dignidad, logrando crear una moralidad política liberal que respeta los derechos civiles y patrimoniales de las minorías sexuales, para efectos de generar la igualdad de género en temas concernientes a las nuevas formas socio jurídicas de la familia en Colombia.

\section{LA IGUALDAD DE GÉNERO EN EL NEOCONSTITUCIONALISMO}

Sostener que la declaración y consagración de los derechos de las personas establece reivindicaciones democráticas, es la tendencia común del nuevo Derecho constitucional (Bohrt, 2006). Es entonces el reconocimiento de los derechos en todos los ámbitos de la vida social; se trata, por tanto, no solo de la igualdad jurídica entre hombres y mujeres, sino de cimentar una sociedad en la que las relaciones entre ambos géneros, en las diferentes actividades sociales, políticas, económicas, laborales, etc., sean ecuánimes.

Así las cosas, un escenario predilecto para el análisis e incorporación de esta reivindicación es, no cabe duda, el de la Constitución Política. Desde la óptica tradicional del pacto social o desde el enfoque sartoriano de la ingeniería constitucional, parece incuestionable que la mayor o menor vigencia real de la equidad de género estará también condicionada por la 
forma como se inserte el tema en el texto constitucional (Bramsted-Melhuish, 1984).

Esta afirmación, empero, no implica caer en una visión juridicista de la discriminación social en función del sexo (hombres y mujeres). Ésta, indisputablemente, tiene raíces económicas, políticas y culturales que, históricamente, han concordado una relación de poder entre hombres y mujeres que -como toda relación de poderimplica inequidad entre unos y otras (MorelloStiglitz, 1986).

Así, la reclamación democrática en pos de la equidad de género se muestra plenamente como lo que es: una reivindicación política, cuya conquista e implantación se basa en y viene generando aquello. Y continuará haciéndolo en el futuro con recónditos cambios societarios (Siegel, 2009). Planteado así el problema y despejado cualesquier maniqueísmo legalista, no puede negarse, por cierto, que la forma como se incorpore el tema de género en la Constitución serenará el surgimiento de acordadas condiciones jurídicas para su posterior procesamiento en las leyes reglamentarias, las que, a su turno, configurarán el escenario operativo, el de la aplicación práctica, de las acciones sociales en procura de la igualdad efectiva entre hombres y mujeres en ámbito de todas sus relaciones (Bognetti, 2005).

Por consiguiente, no cabe duda de que el análisis del tratamiento que la Constitución hace de esta materia es importante. Y lo es todavía más en momentos en que se debate una reforma que, en el caso colombiano, acuerda una mu- tación constitucional al sistema social y jurídico del matrimonio y sus relaciones descendidas.

Desde esta representación, la familia y el reconocimiento de sus nuevas formas en el Derecho privado es la que más signos alentadores parecen mostrar en cuanto la equidad de género y la dignidad propiamente dicha. De hecho, no existe un solo caso en el que el enfoque propio neoconstitucionalista pueda ser relacionado como abstracto, aunque resulta beneficioso dejar dicho que esto puede deberse más a la imposibilidad de invisibilizar el método tradicional del reconocimiento de derechos, por el simple hecho de "Ser Seres humanos" en un escenario en el que ineludiblemente debe hablarse de ambos géneros, que a una vocación irrefrenablemente igualitaria, como en el caso del constitucionalismo americano y francés.

De esta forma, el neoconstitucionalismo liberal aplicado en Colombia conquista las situaciones pertenecientes a la igualdad de género, pues logra que esta situación sea considerada desde el derecho a la vida en condiciones dignas en comunidad. Con ello consigue replantear y estructurar el ordenamiento jurídico con el menor número de arbitrariedades posibles, en la concepción de una justicia que ha cambiado su significado profundamente, dándose así lo que Zagrebelsky llamaría un "humanismo laico" (Spadaro, 1991), de modo que existe una visión objetiva y suprema desde el ordenamiento subjetivo, e individual desde la concepción de persona como ser humano, donde la violación de derechos permite una defensa de éstos estando por encima de la ley. 
De esta manera, este neoconstitucionalismo ideológico en el plano de la igualdad de género logra en Colombia un modus operandi para la aplicación de diferentes principios que se proyecta enarbolar para eclipsar un ordenamiento consecuente con la humanización del derecho y la dignificación de la persona (Geert, 1987), donde los principios como simplificación de la problemática legal del sujeto son la razón superior que responde a las disyuntivas sociales. Instaurando así una jerarquización de estos mandatos rectores, basados en la supremacía de los derechos humanos, generando un sujeto de derecho a partir de la concepción de ser humano y rompiendo la línea imaginaria de cualquier totalitarismo, legalismo, trato razonable justificado en dogmas tradicionales o tiranía.

Terminantemente, la familia, desde este enfoque del neoconstitucionalismo impregna un matiz disímil al del tradicional Derecho privado, que forja una nueva relación constitucional. Pues si bien, no existe un tratamiento claro en los textos constitucionales del mundo, debe destacarse que tres constituciones -la de Argentina, Francia y Estados Unidos-, aunque no legislan absolutamente nada en relación con la familia, en efecto protegen como garantes el tema de la igualdad de género y sus relaciones familiares derivadas. En definitivo, en nuestro caso, se comprobará cómo en el sistema colombiano el enfoque neoconstitucional de género transformó la dinámica de la legislación interna, que desde el periodo 1886-1990 constituyó la protección de un solo modelo familiar. El sistema neoconstitucional actual creó un método opuesto, propio para el reconocimiento jurídico de las nuevas formas familiares, de cara a la nebulosa del "género", en el ámbito del nuevo Derecho privado constitucional colombiano.

INICIO DEL ENFOQUE DE LA IGUALDAD DE GÉNERO: EL RECONOCIMIENTO JURÍDICO DE LOS DERECHOS DE LAS PAREJAS DEL MISMO SEXO EN COLOMBIA. RECORRIDO JURISPRUDENCIAL

Se estipula que en Colombia existe una línea jurisprudencial modulada por la Corte Constitucional, seguida por la Corte Suprema de Justicia, sobre parejas del mismo sexo (Bonilla, 2008), la cual es dividida en tres partes: reconocimiento, consolidación y expansión.

Respecto al reconocimiento podemos comprobar que está concedido por la sentencia C-075 de 2007, donde el tribunal constitucional por primera vez en la historia del país admitió la existencia jurídica de las parejas del mismo sexo. En ésta, la Corte Constitucional decidió que la Ley 54 de 1990, que regula todas las materias relacionadas con la unión marital de hecho, era aplicable tanto a las parejas heterosexuales como a las del mismo sexo. Fijó asimismo que el artículo 1 de la Ley 54 del 90, que definía la unión marital de hecho como aquella institución compuesta por un hombre y una mujer que cohabitan por al menos dos años, era constitucional únicamente si era aplicable también a las parejas homosexuales.

Desde esta nueva configuración constitucional, la interpretación condicionada del artículo 1 
instituyó que el resto de los preceptos que componen la Ley 54, que normaliza los aspectos patrimoniales de la unión marital de hecho, fueran aplicables a todas las parejas heterosexuales y homosexuales que existen en el país, para efectos de no ofuscar sus garantías fundamentales. Pero, la Corte Constitucional imprimió de manera indiscutible que su decisión se circunscribe únicamente a la ley anteriormente referenciada. Esta tesis resulta de particular importancia pues el artículo 1 de dicha ley era el único que definía de manera clara y precisa la unión marital de hecho en el ordenamiento jurídico colombiano, y establecía un referente ineludible para aclarar el amplio número de preceptos que precisan derechos y obligaciones para las personas que componen uniones maritales de hecho -normas que regulan materias tan distintas como la obtención de la ciudadanía, los seguros de automóviles y la obligación que tienen los padres y madres de proveer una cuota de alimentos para sus hijos-.

De este aspecto, tal como lo asienta y comparte también Bonilla (2008): “Si la Corte Constitucional Colombiana lo hubiera querido, con esta sola sentencia hubiera logrado hacer una transformación global del sistema jurídico colombiano".

De manera que, todas las normas que regulan la unión marital de hecho y sus resultados son aplicables tanto a las parejas heterosexuales como a las parejas del mismo sexo. Si bien esta sentencia no tuvo el efecto deseado, abrió el camino para que nuevas demandas apelaran a cuestionar el estado de cosas inconstitucional respecto a las normas jurídicas que hicieran referencia a la unión marital de hecho heterosexual, que a manera de argumento de exclusión, obviaban la situación jurídica de las parejas del mismo sexo.

La segunda parte de esta línea jurisprudencial está conformada por las sentencias C-811 de 2007, C-336 de 2008, C-798 de 2008, T-856 de 2007 y T-1241 de 2008, las cuales revalidan la regla jurisprudencial constitucional anteriormente definida. Es decir, indican que las parejas del mismo sexo pueden constituir uniones maritales de hecho, ampliando los derechos y obligaciones que están en cabeza de sus miembros. A manera de recuento jurisprudencial: la primera sentencia reconoció que las normas que regulan la afiliación al sistema contributivo de salud de las parejas heterosexuales que conforman una unión marital de hecho, son también aplicables a las parejas del mismo sexo, propugnando los derechos de igualdad y trato humano digno conforme a la Constitución y al régimen constitucional fundamental aplicable en el Estado colombiano. La segunda sentencia, en relación con la misma postura fundamental, señaló también que tanto los miembros de las parejas heterosexuales como las del mismo sexo pueden ser titulares de la pensión de sobrevivientes. La tercera sentencia indicó que tanto los miembros de las parejas del mismo sexo como las heterosexuales pueden ser titulares del derecho a recibir una cuota de alimentos por parte de su pareja, una vez se ha terminado la vida en común. Todo en razón al modelo constitucional diseñado con el fin de defender la igualdad material 
frente a ley, apelando al principio de la dignidad humana.

Las últimas dos sentencias de revisión de tutela corroboran el derecho que tienen los ciudadanos que hacen parte de parejas del mismo sexo a ser afiliados al sistema contributivo de seguridad social, por un lado, y a recibir la pensión de sobreviviente, por el otro. Sentencias que fueron concretadas en sede de control concreto de constitucionalidad (Sentencia T-1241: Corte Constitucional, 2008).

La tercera etapa de esta línea jurisprudencial expande de manera radical el número de derechos y obligaciones que están en cabeza de los miembros de las parejas del mismo sexo. Tiene como único, pero muy importante componente, la sentencia C-029 de 2009. Esta sentencia surge como consecuencia de una demanda que cuestionó la constitucionalidad de 26 normas jurídicas que diferenciaban infundadamente las parejas del mismo sexo y las parejas heterosexuales. En este caso, las normas que la Corte Constitucional declaró constitucionales de manera condicionada en esta jurisprudencia, pueden ser reunidas en los siguientes cinco grupos: penales, civiles y comerciales, seguridad social, políticas, y aquellas relacionadas con el conflicto armado. La Corte señaló que este conjunto de normas jurídicas, dirigidas a las parejas heterosexuales, son constitucionales únicamente si se aplican también a las parejas del mismo sexo, por invocación del principio de la dignidad humana. Interpretación constitucional que se fijó de la siguiente forma: (i) Para el primer grupo de normas, que hace referencia a temas penales tan disímiles como el derecho a no declarar, denunciar o formular queja en contra de los compañeros permanentes en cualquier materia disciplinaria, penal y penal militar (Congreso de la República, Ley 906 de 2004), la Corte Constitucional fijó que a las parejas del mismo sexo les es aplicable el mismo beneficio de prescindir de la sanción penal no privativa de la libertad cuando el sujeto pasivo del delito fuera el compañero permanente, tal como sucede en el régimen vigente de las parejas heterosexuales. Haciendo también extensiva la prerrogativa propia del derecho penal que implica la agravación punitiva para el sujeto activo de una conducta punible, cuando el sujeto pasivo sea el compañero permanente adquiriendo el afectado la calidad de víctima.

(ii) Respecto al segundo conjunto, conformado por normas civiles y comerciales, la Corte Constitucional determinó que los temas como la constitución del patrimonio inembargable de familia (Congreso de la República, Ley 70 1931), la afectación de la vivienda familiar con el fin de proteger los bienes y vivienda de las parejas, y la obligación de pagar una cuota de alimentos al compañero permanente una vez se haya terminado la vida en común, también es aplicable a las relaciones jurídico-patrimoniales de las parejas del mismo sexo. 
(iii) En cuanto al tercer grupo de normas, reunidas bajo la categoría de seguridad social, la Corte Constitucional estipuló que sí existe la posibilidad de que los miembros de las parejas del mismo sexo obtengan los beneficios que en materia de salud y pensiones reciben los miembros de las parejas heterosexuales que pertenecen a la fuerza pública; y que las personas que hacen parte de parejas del mismo sexo podrán obtener los subsidios familiares que reciben los miembros de las parejas heterosexuales, por ejemplo, los de vivienda y educación (Congreso de la República, Ley 21 1982).

(iv) El cuarto conjunto de normas regula las materias relacionadas con el régimen de inhabilidades e incompatibilidades; las restricciones al acceso y ejercicio de la función pública y la contratación estatal dentro del Derecho público constitucional, administrativo y económico; así como la aplicación de los requisitos para adquirir la nacionalidad por adopción. Sobre éstas el alto tribunal de constitucionalidad estimó que igualmente son aplicables sin distinción alguna.

(v) Finalmente, el quinto grupo de normas hace referencia a cuestiones tan importantes como el derecho que tienen los compañeros permanentes de las personas que han sido sujetos pasivos de delitos atroces, a que se presuman como víctimas y que, por tanto, tengan derecho a la verdad, justicia y reparación. Estimó la Corte que son igualmente aplicables, pues no existe dentro del sistema penal colombiano una justificación que permita tratarlos de una forma diferente.

Así entonces, la línea jurisprudencial articulada por la Corte Constitucional en estas siete sentencias es consistente. Todas parten de la premisa que indica que los miembros de las parejas del mismo sexo son sujetos de derecho y, por ende, titulares de un conjunto importante de obligaciones y derechos particulares apelando al concepto de la dignidad humana y trato ecuánime digno dentro de las relaciones jurídicas. Del mismo modo, los siete fallos se fundan en los tres pilares jurídicos que fueron fijados por la sentencia C-075/2007: dignidad, libre desarrollo de la personalidad e igualdad. Categorías jurídicas que son definidas por la Corte Constitucional apelando a interpretaciones del liberalismo político-constitucional (Bramsted-Melhuish, 1984).

\section{EL MÉTODO NEOCONSTITUCIONAL DE LA DIGNIDAD EN EL ÁMBITO DE LAS RELACIONES FAMILIARES Y DE GÉNERO EN COLOMBIA}

Al analizar la figura del neoconstitucionalismo liberal, que impregna su matiz jurídico en el enfoque de género aplicado en Colombia por la jurisprudencia de la Corte Constitucional al reconocer los derechos de las parejas del mismo sexo como reivindicación pública establecida por los cambios concretos del constitucionalismo social en la Constitución de 1991, es plau- 
sible también citar lo señalado por la profesora Yadira Alarcón Palacio quien establece que:

"la normativa garantista actual del derecho de las personas y la familia en Colombia si bien fija fundamentos y avances considerables, aún no forma medidas de restablecimiento de derechos absolutos aplicables" (Alarcón, 2011).

Siguiendo este perfil que propugna la búsqueda de la total igualdad en derechos de las minorías sexuales y de género, mantenido en Colombia por la doctora Alarcón Palacio, en cuanto a estipular que los ordenamientos jurídicos civiles en sus jurisdicciones deben optar por el modelo jurídico-jurisdiccional del neoconstitucionalismo liberal, anteriormente Ilamado Activismo Judicial, el cual permite dirimir los conflictos con formas nuevas del derecho civil, presento un modelo que, aunque creado y aplicado en Colombia de forma jurisprudencial a instancia de la jurisdicción constitucional, logra aportar un procedimiento alterno al problema del reconocimiento de nuevas formas jurídicas en materia de persona, familia y género en el derecho civil contemporáneo (Rodríguez, 2002).

Típicamente este modelo gira en torno al principio de la dignidad humana, máxima madre de las relaciones ecuánimes en todo Estado de derecho, que incluso subsume al derecho a la igualdad. Este principio señala, como se ha dicho antes, que todos los seres humanos somos dignos en tanto que tenemos la capacidad de proferir, cambiar y realizar, haciendo uso de la razón, proyectos de buen vivir y de justicia. Es decir que, como lo señala continuamente la jurisprudencia de la Corte Constitucional sobre parejas del mismo sexo, los miembros de la especie humana somos iguales en tanto que somos fundamentalmente seres autónomos y racionales.

Estas capacidades comunes son vulneradas, arguye el modelo de la dignidad, cuando el ordenamiento jurídico no reconoce a las parejas del mismo sexo en plano de la igualdad de género. Los proyectos de buen vivir de la mayoría de las personas ciñen una dimensión de vida en pareja, que se niega de manera radical para los individuos con orientaciones sexuales alternativas. Desde este aspecto, el Derecho constitucional y la corriente del neoconstitucionalismo liberal, pactan que el Estado con este tipo de omisión está soslayando que las personas tomen autónomamente una decisión sobre el tipo de vida que quieren vivir, lo que en últimas no puede afectar negativamente los derechos de terceras personas.

De esta forma, el sistema constitucional de frente a las reglas del nuevo Derecho privado, es decir, el Derecho privado constitucional aplicado a las personas y la familia, decreta la existencia de una limitación radical e injustificada de la potestad misma de escoger libremente un proyecto de vida, institución social que el mismo sistema jurídico de Derecho civil ha protegido desde tiempos inmemoriales. El Estado, entonces, con su inacción, está indicando que prefiere una orientación sexual -la heterosexual- por sobre otra -la homosexual-y, que, por tanto, los individuos deberían escoger la primera y no la segunda, coartando el status libertatis (Valiño, 1977) de carácter privado y personalísimo propugnado 
por el Derecho civil y sus codificaciones, antes que el constitucionalismo contemporáneo lo recogiera en las principales cartas políticas estatales, como derecho fundamental.

Así entonces, la cuestión no es sólo que las personas consigan vivir con la pareja de su elección sin que el Estado las sancione, sino que éste reconozca la vida de las parejas del mismo sexo como una alternativa válida para la comunidad política y jurídica de orden estatal. Reconocimiento que debe tener un valor jurídico-formal, transcrito en una aceptación de los miembros de las parejas del mismo sexo como seres humanos iguales a los heterosexuales; y un valor jurídico-sustancial concerniente a la reducción de los costos patrimoniales de la vida en pareja y la depreciación de la discriminación y la violencia en contra de las parejas del mismo sexo.

El modelo de la dignidad así entendido promete varias ventajas. De forma jurídica, es una ordenación normativa comprehensiva que contiene tanto una extensión de igualdad como una de autonomía. Si bien es claro, este modelo no es fruto de un eclecticismo social débil que busca combinar el modelo de la igualdad con una reinterpretación del modelo de la autonomía, pues la igualdad y la autonomía se aparejan estructuralmente en el concepto de dignidad humana. De hecho, los derechos de igualdad y del libre desarrollo de la personalidad son instrumentos que se derivan y sirven para la defensa de la dignidad.

Esta igualdad es una función de la autonomía y la racionalidad de que gozan todos los individuos. En concepciones básicas, la igualdad es un derecho que otorga las herramientas para evaluar cuándo es legítimo que los miembros de la comunidad política sean tratados de forma desigual y cuáles serían las razones que permitirían cuestionar o fundamentar tales distinciones. A contrario de la autonomía, quien se entiende como una facultad básica que tienen todos los seres humanos y que sólo puede ejercerse de manera efectiva si se cumplen dos requisitos: (i) la satisfacción de algunas necesidades materiales básicas, como la de ingerir cierto número de calorías diariamente, y (ii) la existencia de un marco jurídico-político amplio y respetuoso de los diversos proyectos de buen vivir que son posibles dentro de la comunidad. Conclusión: que los ciudadanos tengan la potestad real de escoger los que consideren más valiosos de entre ellos. Por lo que queda desvirtuada cualquiera postura que justifique que este modelo es producto del eclecticismo social y las combinaciones que propone, pues nada justifica una combinación entre igualdad y autonomía. En efecto, sí es posible determinar que la dignidad incluye, en los términos de la Corte Constitucional colombiana, tres dimensiones que se entrecruzan: el derecho a vivir como se quiera, el derecho a vivir sin humillaciones y el derecho a un mínimo vital. Es decir, que la dignidad incluye a la igualdad y la autonomía pues éstas, en últimas, son extensiones propias del gran principio de la dignidad humana. Respecto a esto, tendremos que ahondar en una de las principales problemáticas que podría presentar este modelo. La llamada vaguedad del principio de dignidad y la posibilidad de fundamentarlo desde diversas representaciones. 
Es cierto que la característica de la dignidad humana como principio fundamental del derecho lo convierte en un espacio discursivo privilegiado para alcanzar acuerdos amplios dentro de una comunidad política plural (Siegel, 2009). El alto grado de generalidad del principio podría interpretarse en contra de la defensa del mismo. El significado de la dignidad humana se podría argumentar de muchas formas puesto que depende del intérprete y, por tanto, está a merced de las relaciones de poder que existen dentro de la comunidad política y de la ordenación sociocultural del Estado. Pero, contamos con un consuelo jurídico: esta es una característica típica de todos los principios - no solo del de dignidad humana-. Hay que hacer hincapié en que la vaguedad de los principios no es duradera. A medida que son interpretados particularmente por operadores jurídico-políticos con autoridad, -como son las cortes Suprema y Constitucional colombianas-, su contenido se va estrechando.

Este contenido se vuelve obligatorio y, por consiguiente, se convierte en una guía para la conducta de las personas. Del mismo modo, el reconocimiento preciso del principio por parte de estos órganos tiene un carácter contingente que permite su variación como consecuencia de las transformaciones que vive la comunidad política. Igualmente, es meritorio aludir que el principio se puede llenar de contenido, fundamentándose en distintos tipos de argumentos -morales y seculares, religiosos e históricos-. Un número extenso de personas puede consentir que es un principio que vale la pena amparar, y entrar en procesos deliberativos que tengan como obje- tivo precisar su contenido y aplicación a casos específicos.

Así, las personas que creen que el principio de dignidad humana debería salvaguardarse porque es una consecuencia de que los seres humanos hayan sido creados a imagen y semejanza de la Divinidad Suprema, en términos judío-cristianos conforme al Génesis 1:26 (Nolte, 2005); quienes creen que la autonomía y racionalidad son características fundamentales de los seres humanos de conformidad con la filosofía propia de la razón (Gewirth, 1992); y quienes discurren que este es un principio cimentado históricamente para defender bienes que nos parecen valiosos, pueden estar de acuerdo en que la dignidad es uno de los ejes en torno a los cuales debe estructurarse una comunidad política (Rao, 2008), lo que abre puertas de solución a la nebulosa jurídica de las parejas del mismo sexo y minorías sexuales.

Desde la anterior perspectiva, el modelo de la dignidad expone de manera clara, precisa y llana el problema que está en juego, resolviéndolo e interpretándolo de modo que entronque con una interpretación iluminadora de la tradición política que sustenta el ordenamiento políticojurídico colombiano: EL LIBERALISMO. Pues en últimas este modelo logra:

1. Coordinar de forma comprensiva de acuerdo con los postulados filosóficos, sociales, morales y religiosos que se detenten en la sociedad civil, la percepción sobre la protección del individuo apelando a la dignidad desde distintas corrientes del pensamiento. Todas aceptadas desde 
el plano socio-cultural y sus respectivas justificaciones.

2. Coordinar de forma sistemática el pensamiento filosófico, social, moral y religioso de conformidad con el sistema jurídico y los derechos, pues este modelo propugna la protección del individuo como sujeto de la especie humana, merecedor de derechos y sujeto de obligaciones.

3. Coordinar la eficiencia con respecto a la corriente iusfilosófica del pensamiento liberal, como un ordenamiento jurídico receptor de los cambios en la sociedad.

Así discurrido, aunque otros modelos como lo son la igualdad y la autonomía, utilizados en su momento por la Corte Constitucional y la Corte Suprema de Justicia, permiten ofrecer una serie de herramientas conceptuales útiles para aproximarnos al problema del no reconocimiento jurídico de las parejas del mismo sexo $\mathrm{y}$, en particular, a la discriminación por razones de orientación sexual; en general, no podemos olvidar que el fin último no es interpretar más ricamente el problema sino eliminarlo en la práctica. En el caso colombiano, ambas cortes (Suprema y Constitucional) en su jurisprudencia aplican el modelo de la dignidad humana para efectos de dar solución parcial, y en el futuro total, a la problemática, basadas en las características eficaces del modelo.

De esta suerte, han venido creando derechos y deberes a manera de estatuto civil y fundamental, aceptados dentro del código ético y social de la comunidad, en procura del reconocimiento absoluto y jurídico de las parejas del mismo sexo desde cualquier percepción científica, social y filosófica. Dado que el principio de la dignidad humana gozó en el ordenamiento jurídico colombiano de vaguedad, la jurisdicción constitucional se encargó de nutrirlo con un pensamiento pluriparticipativo que constatará la aceptación en todas las esferas del conocimiento. Así, aunque el asunto de los derechos de las parejas del mismo sexo no es solo de claridad, precisión y sutileza jurídico-filosófica, sino de lucha política, de construcción de una sociedad más igualitaria en donde la dignidad de todas las personas sea efectivamente protegida, el modelo de la dignidad humana se presenta como una herramienta útil del Derecho civil contemporáneo para erradicar el problema del reconocimiento de nuevas formas jurídicas en materia de persona y familia en el mundo.

\section{EL MÉTODO NEOCONSTITUCIONAL DE LA DIGNIDAD Y LA SENTENCIA C-577 DE 2011}

Es claro concebir, de conformidad con lo anteriormente exhibido, cómo el método de la dignidad, que el representativo reconocimiento constitucional de las minorías sexuales, en el ámbito de sus derechos fundamentales, es una conquista parcial de las garantías aplicables a las personas que se localizan en el plano de la acometida igualdad de género. En efecto, el método de la dignidad logra, constitucionalmente, devastar cualquier tipo de violación de los derechos fundamentales de la persona humana, como prototipo indefectible de la operatividad jurídica de la 
dignidad en su sentido más extenso, desarrollado por la Corte o tribunal constitucional.

De resultas, en un fallo reverenciado como histórico, la Corte Constitucional colombiana fijó todo lo que anteriormente se determinó como método de la dignidad humana en el ámbito del Derecho de las relaciones familiares del mismo sexo. Un fallo trascendental donde el alto tribunal constitucionalizó el apotegma: "las parejas homosexuales constituyen familia", condescendiendo un plazo de dos años para que el Congreso de la República aborde a crear los mecanismos necesarios para legislar sobre la materia. Punto de partida para la solución al problema de la igualad de género en el ámbito de las relaciones familiares en Colombia.

Esta representación constitucional, si bien es un caso de control abstracto de constitucionalidad, giró en torno a la interpretación del alcance del inciso primero del artículo 42 de la Carta Política colombiana, con el fin de prescribir si el matrimonio, en la forma como se define por el artículo 113 del Código Civil colombiano, repudia derechos constitucionales de las parejas que se constituyen por personas del mismo sexo, según lo aducido en las dos demandas de inconstitucionalidad sobre las que se resuelve en este proceso. La Corte emprende por hacer énfasis en el carácter literal de las interpretaciones y reivindica el texto aprobado por el constituyente, que desiguala entre la familia como institución anterior al Estado, de raigambre sociológica, reconocida jurídicamente, y el matrimonio que genera un vínculo fundado en la expresión del consentimiento de los contrayentes que libremente se obligan para constituir una familia.

Al mismo tiempo, parte de un concepto amplio de familia fundado en la consagración de un modelo de Estado social de derecho participativo y pluralista como el contemplado en el artículo $1^{\circ}$ de la Carta, que encierra dentro de los fines enunciados en el artículo $2^{\circ}$, la protección de las libertades, creencias y derechos de todas las personas; derechos que según el artículo $5^{\circ}$ son inalienables y tienen primacía, además que proclama en los términos del artículo $7^{\circ}$ de la Carta, el reconocimiento y protección de la diversidad cultural de la nación, rotundamente contraria a la imposición de un solo tipo de familia y a la consiguiente exclusión de las que no reúnen las condiciones de la que, supuestamente, es la única reconocida y protegida.

Desde esa perspectiva, la Corte señaló que del texto del inciso primero del artículo 42 de la Carta Política no se puede deducir que el constituyente haya consentido un solo modelo de familia, originado exclusivamente en el vínculo matrimonial, pues la convivencia puede crear también la unión marital de hecho, en cuyo caso los compañeros permanentes ya constituyen familia; o crear formas de familia monoparentales, encabezadas solamente por el padre o por la madre; o aún las ensambladas, que se conforman cuando uno de los cónyuges o compañeros ha tenido una relación previa de la cual han nacido hijos que ahora entran a formar parte de la nueva unión, de manera que en su ciclo vital una misma persona puede experimentar el paso por diversas clases de familia. 
En este sentido, y de conformidad con la norma constitucional, la institución familiar en palabras de la Corte Constitucional puede tener diversas manifestaciones que se constituyen, a su vez, a través de distintos "vínculos naturales o jurídicos", según lo previsto en el precepto superior. De ahí que la heterosexualidad no sea una característica predicable de todo tipo de familia y tampoco lo sea la consanguinidad, como lo demuestra la familia de crianza. Ahora bien, aunque es evidente que la jurisprudencia constitucional ha venido reconociendo gradualmente una serie de derechos a las parejas conformadas por personas del mismo sexo, la Corte encontró que los efectos de orden personal que tienen que ver con ciertos derechos y obligaciones surgidos entre los integrantes de la pareja no han sido objeto principal de estas decisiones.

Al analizar la relación entre las parejas homosexuales y la familia, la Corte Constitucional puso de presente que la posición tradicional de la jurisprudencia solo había reconocido como familia a la heterosexual, constituida a partir del matrimonio o de la unión marital de hecho, y que aun cuando ha habido protección a los homosexuales y especialmente a la pareja, sobre todo a partir de la Sentencia C-075 de 2007, esa protección no había alcanzado a variar el concepto tradicional de familia constitucionalmente protegida, que había sido atado a la heterosexualidad de la pareja, como se advierte incluso en las sentencias que han brindado protección a la pareja homosexual. Lo anterior es muestra de la aplicación del método de la dignidad, en el entendido que la Corte Constitucional estipuló su interpretación fijando que una visión jurídica como la anteriormente referenciada, es completamente oponible a la pluralidad de familias distintas de la heterosexual que, incluso, han hallado protección en sede de tutela, así como a la evolución del concepto de familia y a su carácter maleable, lo que llevó a considerar la variación de la interpretación tradicional del artículo 42 superior, para que responda de mejor modo a la realidad actual.

Lo anterior, entonces, no es más que el reconocimiento por parte de la Corte Constitucional del status libertatis de carácter privado y personalísimo, propugnado por el Derecho civil y sus codificaciones, al estipular que tal reconocimiento no es tanto la expresión excelsa de que las personas consigan vivir con la pareja de su elección sin que el Estado las sancione, sino que éste reconozca la vida de las parejas del mismo sexo como una alternativa válida para la comunidad política y jurídica de orden estatal, lo que antecedentemente se justificó dentro del método. Interpretación que llevó a la Corte a la conclusión valedera de que no existen razones jurídicamente atendibles que permitan sostener que entre los miembros de la pareja del mismo sexo no cabe predicar el afecto, el respeto y la solidaridad que inspiran su proyecto de vida en común, con vocación de permanencia, o que esas condiciones personales merecen protección cuando se profesan entre personas heterosexuales, mas no cuando se trata de parejas del mismo sexo.

En esta perspectiva y a su juicio, el método de la dignidad llevó a la Corte Constitucional a fijar que la protección a las parejas homosexuales 
no puede quedar limitada a los aspectos patrimoniales de su unión permanente, pues hay un componente afectivo y emocional que estimula su convivencia y que se traduce en solidaridad, declaraciones de afecto, socorro y ayuda mutua, elementos personales que se encuentran en las uniones heterosexuales o en cualquier otra unión que, pese a no estar definida por la heterosexualidad de quienes la conforman, constituye familia. (i) De esta forma, el tema de la desigualdad de género, desde el plano de la constitución de familia en Colombia, fue desvirtuado en sede constitucional.

En ese mismo contexto, la Corte precisó que es claro que al mismo tiempo que la Constitución no concibió una sola forma de familia, fundó de manera expresa el matrimonio como una de las varias modalidades de conformarla, referida a la "decisión libre de un hombre y una mujer". Es decir, el matrimonio, como una de las formas de constituir una familia, aparece aquí ligado a la pareja heterosexual, sin que ello implique la exclusión absoluta de la posibilidad de que el legislador regularice la manera como se debe formalizar y solemnizar un vínculo jurídico entre las parejas del mismo sexo que libremente quieran hacerlo, reservándose la libertad de establecerle el nombre que quiera darle a dicho vínculo. Esto significa que la forma matrimonial prevista en el artículo 113 del Código Civil para las uniones heterosexuales, es por excelencia una posibilidad legítima y válida, acorde con lo previsto en el inciso primero del artículo 42 de la Constitución.
Pero también es válido precisar que, tratándose de este método, "el de la dignidad”, predestinado a generar el reconocimiento de la relación de igualdad de género en el plano de la reciprocidad familiar (pareja del mismo sexo), la Corte constitucionalizó la validez fundamental que consistirá en el reconocimiento jurídico que tendrán las parejas del mismo sexo en Colombia, cuando motivadas a legalizar su compromiso marital pretendan vincularse al régimen matrimonial. Así pues, la Corte le dio un valor jurídico-formal, transcrito en una aceptación de los miembros de las parejas del mismo sexo como seres humanos iguales a los heterosexuales; y un valor jurídico-sustancial concerniente a la reducción de los costos patrimoniales de la vida en pareja y la depreciación de la discriminación y la violencia en contra de las parejas del mismo sexo, es decir, legalidad y/o formalidad propiamente dicha, ya que, en la eventualidad de que el Congreso de la República no legisle, las personas del mismo sexo podrán acudir posteriormente ante notario o juez competente para formalizar y solemnizar su unión mediante vínculo contractual, subsanando así la problemática sobre la protección que merecen, para efectos de generar la igualdad de género. (ii) De esta forma, el tema de la desigualdad de género, desde el plano de la constitución de una relación marital formal en Colombia, fue desvirtuado en sede constitucional.

Lo anterior, bajo el entendido de que la interpretación del artículo 42 constitucional permite que ambas posibilidades concurran. No obstante, al no existir actualmente en el ordenamiento jurídico colombiano una forma específica para 
formalizar las uniones con vocación de permanencia entre personas del mismo sexo, la Corte constata la existencia de un déficit de protección de sus derechos que, en primera instancia y en armonía con el principio democrático, debe ser atendido por el legislador, dentro del ámbito de su competencia para desarrollar la Constitución Política y adoptar medidas que garanticen el goce efectivo de los derechos de las parejas del mismo sexo.

Por lo expuesto, la Corte procedió a declarar exequible la expresión "un hombre y una mujer" contenida en el artículo 113 del Código Civil, y a exhortar al Congreso de la República para que antes del 20 de junio de 2013 legisle, de manera sistemática y organizada, sobre los derechos de las parejas del mismo sexo con la finalidad de eliminar el déficit de protección que las afecta. El fundamento de la decisión fue, simple y Ilanamente: dignidad. Pues partiendo del equilibrio que debe existir entre el principio democrático que supone que el Congreso es el máximo representante de la voluntad popular, y, la vigencia permanente de los derechos constitucionales fundamentales de los ciudadanos, no deben existir violaciones que tácitamente ofusquen las garantías de los aplicables a ellos.

Definitivamente, lo anterior no es más que un progresivo cambio de paradigma en la propia autoconcepción del rol institucional del máximo tribunal, órgano que ahora se afirma para evidenciar su mayor activismo en materia de protección de los derechos humanos, en el campo de la elección de los medios más adecuados para lograr las finalidades del bien común usando, sin duda, la vía apta para llegar a decisiones al menos aceptables en virtud del compromiso, o de la imposición de la mayoría, como en el caso de la igualdad de género en el plano de la relación familiar del mismo sexo. De esta forma, se trata de precisar que el contenido de los derechos humanos fundamentales es una conquista preeminente de la Corte Constitucional, a cuyos integrantes corresponde desempeñar una de las funciones primordiales de la actividad jurídica de un Estado de derecho, que como en este fallo han garantizado moderadamente: el respeto de los derechos humanos de las personas frente al poder del Estado y de quienes detectan la facultad primaria de ser "mayoría".

\section{CONCLUSIONES}

1. Es meritorio admitir que la Corte Constitucional colombiana expresa y aporta hoy al Derecho civil importantes novaciones que se han traducido en cambios sociales y culturales dentro de la interpretación del ordenamiento privado en Colombia. Es decir, está proveyendo un comienzo garantista en torno a la valoración social de las minorías sexuales, en temas concernientes a las relaciones género-familia.

2. El giro jurídico a manera de cambio, con respecto a la condición y reconocimiento de las parejas del mismo sexo, y otros derechos anexos a las minorías sexuales en Colombia desde el plano de las relaciones familiares, se corrobora por la definición 
de una extensa línea jurisprudencial obligatoria, con un fallo que define "constitucionalmente" la legalidad de su existencia y la validez fundamental conforme al régimen constitucional. Línea que ha sido aceptada dentro de las principales plataformas y códigos ético-morales de corte social y religioso al interior del Estado colombiano, y con la cual se logra una mejor comprensión, apreciación y tramitación del problema que genera el no reconocimiento jurídico de las parejas del mismo sexo en Colombia.

3. El modelo de la dignidad aplicado como solución al problema del reconocimiento de las parejas del mismo sexo y otros derechos de las minorías sexuales en temas concernientes a género y familia, accede que el ordenamiento civil gire en torno al principio de la dignidad humana, logrando que las minorías sexuales también puedan ser dignas de la capacidad de proferir, cambiar y realizar sus proyectos de buen vivir y de justicia, bajo el entendido que este modelo propugna una perspectiva jurídica que comprende la necesidad civil y patrimonial de estipular un reconocimiento que contiene, tanto una extensión de igualdad como una de autonomía, en las decisiones de las personas que conforman el Estado.

4. Finalmente, el asunto de los derechos de las parejas del mismo sexo y de las minorías sexuales en el plano del reconocimiento de las relaciones familiares, a manera de lucha política, ha sido regularmente superado para efectos de construir una sociedad más igualitaria a través del modelo de la dignidad. La Corte, al definirlas (parejas del mismo sexo) como "familia" con legitimidad constitucional para establecer y formalizar un "matrimonio civil" con todos los efectos jurídicos sobrevinientes, aplicó un insumo útil del Derecho civil contemporáneo para exterminar el problema del reconocimiento de nuevas formas jurídicas en materia de persona y familia, en el plano de la igualdad de género en el mundo.

\section{Bibliografía}

Alarcón-Palacio, Yadira. (2011). Constitucionalismo y garantismo en los derechos de la infancia y la adolescencia en Colombia. 122 Vniversitas, pp. 363-394.

Aznar, P. y Cánovas, P. (2008). Educación, género y políticas de igualdad. Valencia: Universitat de Valencia.

Bognetti, Giovanni. (2005). The concept of Human Dignity in European and US Constitutionalism. En: Nolte, Georg (ed.). European and US Constitutionalism. Cambridge: Cambridge University Press, p. 89.

Bonilla, Daniel. (2008). Igualdad, orientación sexual y derecho de interés público: la historia de la sentencia C-075/07. En: Parejas del mismo sexo: el camino hacia la igualdad. 
Bogotá: Universidad de los Andes-Colombia Diversa.

Bramsted, E.K. y Melhuish, K.J. (1984). El liberalismo en Occidente: historia en documentos. Tomo 1. Madrid: Unión Editorial.

Camargo, Pedro Pablo. (1983). Nuevo Constitucionalismo. En: Tratado de Derecho Constitucional General. Bogotá: Temis.

Estrada-Vélez, S. I. (2005). Los principios jurídicos y el Bloque de Constitucionalidad. Medellín: Universidad de Medellín.

Gewirth, Alan. (1992). Human Dignity as the Basis of Rights. En: Meyer, Michael J. y Parent, William A. (Eds.). The Constitution of Rights: Human Dignity and American Values. Ithaca, N.Y: Cornell University Press, 1992, pp. 99-109.

Loerbaum, Yair. (2008). Blood and the Image of God: On the Sanctity of Life in Biblical and Early Rabbinic Law. Myth and Ritual. In The concept of Human Dignity in Human Rights Discourse 56.

Morello, Augusto M. y Stiglitz, Gabriel. (1896). Tutela procesal de derechos personalísimos e intereses colectivos. Buenos Aires: Ed. Platense.

Rao, Neomi. (2008). On the Use and Abuse of Dignity. Constitutional Law. Columbia Journal of European Law. 14 (2): pp. 201- 256; George Mason Law \& Economics Research. Paper No. 08-34.
Rodríguez Guitián, Alma María. (2002). Del derecho civil decimonónico al derecho civil contemporáneo. Estudios jurídicos en homenaje al profesor Luis Díez-Picazo. Vol. 1. Madrid: Editorial Semblanza, págs. 845-860.

Sáchica, Luis Carlos. (2000). Constitucionalismo colombiano. Bogotá: Temis.

Santo Tomás. (1968). Suma Teológica. Tomos VI y VIII. Madrid: BAC.

Siegel, Reva B. (2009). Dignity and the Politics of Protection: Abortion Restrictions Under Casey/Carhart. Yale Law Journal 117: 101.

Siegel, Reva B. (2008). La dignidad y el debate del aborto. SELA, p. 10.

Spadaro, A. (1991). II problema del "fondamento" dei diritti "fondamentali", en Diritto e societa, pp. 45 ss.

Valiño, Emilio. (1977). Instituciones de derecho privado romano. Valencia: Departamento de Derecho Romano de la Universidad de valencia.

\section{Bibliografía orientadora}

Aragón Reyes, Manuel. (1986). Sobre las nociones de supremacía y supralegalidad constitucional. Bogotá: Editorial Universidad Externado de Colombia, p. 36.

Carré de Malberg, R. (1998). Teoría general del Estado. ( $2^{\mathrm{a}}$ ed. en español). José Lion Depetre (trad.). México: Universidad Nacional 
Autónoma de México, Facultad de DerechoFondo de Cultura Económica.

Comanducci, Paolo. (2002). "Formas de Neoconstitucionalismo: un Análisis Metateórico". En: Isonomia. Revista de Teoría y Filosofía del Derecho N 16, pp. 89 a 112.

Dalla Vía, Alberto Ricardo. (1994). Transformación económica y seguridad jurídica. Buenos aires: Ed. Platense.

Gambino, S. (Coord.). (2006). Trattato che adotta una Costituzione per l'Europa, Costituzioni Nazionali, Diritti Fondamentali. Milán: Giuffrè.

García Pelayo, Manuel. (2002). Derecho constitucional comparado. Madrid: Revista de Occidente.

González, Joaquín V. (1999). Manual de la Constitución argentina. Buenos Aires: Estrada.

Hesse, K. (2005). Escritos de derecho constitucional. Madrid: Centro de Estudios Constitucionales, 1983.

Loewenstein, Karl. (1999). Teoría de la Constitución. Barcelona: Ariel.

Meyer, Michael J. y Parent, William A. (Eds.). The Constitution of Rights: Human Dignity and American Values. Ithaca, N.Y: Cornell University Press.

Rawls, John. (1996). Teoría de la justicia. México: Fondo de Cultura Económica.
Sagues, Néstor P. (2001). Elementos de derecho constitucional. T. 2. Buenos Aires: Astrea.

Smith, Erik L. (1997). Landmark Cases in Adoption Law. In: Harvard Law School, Ed. 16.

Zarini, Helio Juan. (1994). Constitución argentina comentada y concordada. Texto según la reforma de 1994. Buenos Aires: Astrea.

JURISPRUDENCIA Y LEYES

COLOMBIA

CORTE CONSTITUCIONAL

SENTENCIA C-075 DE 2007.

SENTENCIA C-811 DE 2007.

SENTENCIA T-856 DE 2007.

SENTENCIA C-336 DE 2008.

SENTENCIA C-798 DE 2008.

SENTENCIA T-1241 DE 2008.

SENTENCIA C-029 DE 2009.

SENTENCIA C-577 DE 2011.

Constitución Política.

Código Civil.

Ley 70 de 1931.

Ley 3 de 1991. 
Ley 5 de 1992.

Ley 43 de 1993.

Ley 190 de 1995;

Ley 294 de 1996

Ley 258 de 1996.

Ley 599 de 2000.
Ley 906 de 2004.

Ley 923 de 2004.

Ley 522 de 1999.

Ley 734 de 2002.

Ley 1148 de 2007.

Ley 1153 de 2007.

Decreto 1795 de 2000. 